\title{
Differences in outpatient care and treatment utilization for patients with HIV/HCV coinfection, HIV, and HCV monoinfection, a cross-sectional study
}

Terence L Johnson ${ }^{1}$, Joshua C Toliver ${ }^{1}$, Lu Mao $^{2}$ and Christine U Oramasionwu ${ }^{1 *}$

\begin{abstract}
Background: Few studies have explored how utilization of outpatient services differ for HIV/HCV coinfected patients compared to HIV or HCV monoinfected patients. The objectives of this study were to (1) compare annual outpatient clinic visit rates between coinfected and monoinfected patients, (2) to compare utilization of HIV and HCV therapies between coinfected and monoinfected patients, and (3) to identify factors associated with therapy utilization.

Methods: Data were from the 2005-2010 U.S. National Hospital Ambulatory Medical Care Surveys. Clinic visits with a primary or secondary ICD-9-CM codes for HIV or HCV were included. Coinfection included visits with codes for both HIV and HCV. Monoinfection only included codes for HIV or HCV, exclusively. Patients $<15$ years of age at time of visit were excluded. Predictors of HIV and HCV therapy were determined by logistic regressions. Visits were computed using survey weights.
\end{abstract}

Results: 3,021 visits (11,352,000 weighted visits) met study criteria for patients with HIV/HCV (8\%), HIV (70\%), or HCV (22\%). The HCV subgroup was older in age and had the highest proportion of females and whites as compared to the HIV/HCV and HIV subgroups. Comorbidities varied significantly across the three subgroups (HIV/HCV, HIV, HCV): current tobacco use (40\%, 27\%, 30\%), depression (32\%, 23\%, 24\%), diabetes (9\%, 10\%, 17\%), and chronic renal failure $(<1 \%, 3 \%, 5 \%)$, $(p<0.001$ for all variables). Annual visit rates were highest in those with HIV, followed by HIV/HCV, but consistently lower in those with HCV. HIV therapy utilization increased for both HIV/HCV and HIV subgroups. HCV therapy utilization remained low for both HIV/HCV and HCV subgroups for all years. Coinfection was an independent predictor of HIV therapy, but not of HCV therapy.

Conclusion: There is a critical need for system-level interventions that reduce barriers to outpatient care and improve uptake of HCV therapy for patients with HIV/HCV coinfection.

Keywords: HIV, HCV, Coinfection, Antiretroviral, Antiviral, Therapy, Utilization

\section{Background}

Human Immunodeficiency Virus (HIV) and hepatitis C virus $(\mathrm{HCV})$ monoinfection have been the subjects of ample research over the past two decades; however, $\mathrm{HIV} / \mathrm{HCV}$ coinfection has only recently been documented as a growing medical concern in the United States [1].

\footnotetext{
* Correspondence: oramsc@unc.edu

'University of North Carolina, UNC Eshelman School of Pharmacy, Division of Pharmaceutical Outcomes and Policy, Chapel Hill, NC 27599-7355, 2215 Kerr Hall, USA

Full list of author information is available at the end of the article
}

Combination HIV antiretroviral therapy and combination $\mathrm{HCV}$ antiviral therapy have been recommended since the late 1990s, as they each greatly reduce patient morbidity and mortality $[2,3]$. While antiretroviral and antiviral therapies are widely recommended for use in patients with coinfection [4], these patients continue to experience poorer health outcomes than those with monoinfection. For instance, these individuals are at increased risk for accelerated progression of liver disease and increased rates of morbidity and mortality $[5,6]$.

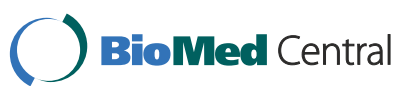


If patients with coinfection do not utilize outpatient services to the extent that patients with HIV or HCV utilize these services, consequently, patients with coinfection may not be prescribed therapy to the extent that patients with monoinfection are prescribed therapy. Few studies to date have explored how outpatient health care utilization patterns differ by infection status. Thus, the extent to which patients with coinfection receive care in the U.S. outpatient health care delivery system, as compared to patients with monoinfection, is relatively unknown. The U.S. health care system is based on a multipayer system, whereby, medical care is provided by various independent organizations, rather than a single universal entity. These independent organizations are largely owned and operated by the private sector; however, other players in the market include the U.S. government and other non-profit organizations [7]. The multitude of health care providers can result in various barriers to care, including financial barriers for individuals who are uninsured or underinsured, lack of availability of specialized professionals, and inability to reach providers [7].

The objectives of this study were to compare, between patients with $\mathrm{HIV} / \mathrm{HCV}$ coinfection and monoinfection (HIV and $\mathrm{HCV}$ ), (1) annual outpatient clinic visit rates, (2) trends in yearly outpatient prescription for HCV antiviral therapy and HIV antiretroviral, (3) conduct multivariate analysis to identify factors associated with antiretroviral and antiviral utilization.

\section{Methods}

\section{Data Source}

The 2005-2010 U.S. National Hospital Ambulatory Medical Care Surveys (NHAMCS) were used for this study. The NHAMCS are nationwide probability sample surveys that are conducted annually by the Centers for Disease Control and Prevention (CDC). The NHAMCS are representative of approximately 500 general and pediatric hospital outpatient clinics, while excluding federal, military, veteran affairs, and institutional hospital clinics. Survey data are available to the public and are a national representation of annual clinic visit records. The objective of the NHAMCS is to provide a populationlevel estimate of the utilization of outpatient services in the United States, therefore, some patient level data, such as laboratory results, are not always available. Each record consists of up to three International Classification of Diseases, Ninth Revision, Clinical Modification (ICD-9-CM) diagnosis codes and medication codes that document up to eight medications listed at time of the clinic visit. The outpatient clinic visits are systematically sampled using a multi-stage process conducted by trained field representatives (e.g., health care provider or clinic staff) during a randomly assigned 4-week period. The various study survey error rates typically range between $0.3 \%$ and $0.9 \%$; however, independently selected quality control samples, approximately $10 \%$ of patient record forms, are keyed and coded. Additional information about the NHAMCS data collection process and interpretation are available elsewhere [8].

\section{Study design}

This was a nationally representative, retrospective, crosssectional study. All variables were retrieved from the NHAMCS and included patient demographics (patient age at time of clinic visit, gender, race/ethnicity, geographic region in the United States, insurance status) and visit characteristics (established patient, patient's primary physician/provider, visit diagnosis, year of visit, and providers seen). Insurance status was classified as private, Medicare, Medicaid, self-pay, no charge, or unknown/ other. In the United States, the major insurance payers are private insurance and government in the form of Medicare and Medicaid $[9,10]$. Although both Medicare and Medicaid are examples of government-funded programs, they are funded differently. Medicare is a national program designed to provide medical care for older adults and is funded by the U.S. government. Patients aged 65 or older, with end-stage renal disease, or with certain qualifying disabilities are eligible for Medicare. In contrast, Medicaid is a state-specific program designed to provide health care to low-income patients and is funded on the federal and state level. Patients are eligible for this program if they meet certain criteria, however, this criteria can vary greatly based on the individual state.

Comorbidities were based on additional clinic visit diagnoses to include: chronic renal failure, depression, diabetes, and current tobacco use. All clinic visits with a primary or secondary ICD-9-CM diagnosis code for HIV or HCV were included. The following ICD-9-CM codes were used to identify HIV infection: 042, V08, and 079.53 and the following codes were used to identify HCV infection: 070.41, 070.44, 070.51, 070.54, 070.70, and 070.71. HIV monoinfection visits excluded $\mathrm{HCV}$ ICD-9-CM codes and HCV monoinfection visits excluded HIV ICD-9-CM codes. HIV/HCV coinfection visits included those that had ICD-9-CM codes for both HIV and HCV.

Medication drug codes were determined from the $\mathrm{Na}$ tional Center for Health Statistics (NCHS) drug database to define $\mathrm{HCV}$ antiviral medications and HIV antiretroviral medications. $\mathrm{HCV}$ antiviral medications included any of the following: ribavirin, interferon, or pegylated interferon. HIV antiretroviral medications included any of the following: nucleoside reverse transcriptase inhibitors, non-nucleoside reverse transcriptase inhibitors, protease inhibitors, integrase inhibitors, entry inhibitors, CCR5 antagonists, or other antiretroviral combination products. 
Patients under the age of 15 at time of the clinic visit were excluded. The Ethics Review Board of NCHS approves the NHAMCS on an annual basis. The University of North Carolina Office of Human Research Ethics determined that this project was not considered Human Subjects Research according to regulatory criteria, and, therefore, institutional review board approval was not needed.

\section{Data analysis}

Survey weights for each observation in the survey sample were used to generate national estimates for clinic visits. The survey weights are calculated by $\mathrm{NCHS}$ and are the result of corresponding sampling fractions at each stage in the sample design. The study weights are adjusted for nonresponse within time of year, geographical region, and urban/rural and ownership designations, producing an unbiased national estimate of outpatient visit occurrences, percentages, and characteristics. In addition, weighted estimates account for the cluster and stratum effect of the primary sampling unit (PSU). Weighted clinic visit estimates and disease surveillance estimates were used to calculate annual clinic visit rates (visits per U.S. population with diagnosed infection).

All data analyses were conducted using $\mathrm{JMP}^{\circledR} 8.0$ and $\mathrm{SAS}^{\oplus} 9.2$ (SAS Institute Inc., Cary, NC). A two-tailed alpha-level $<0.05$ was used to determine statistical significance. Demographic characteristics and select comorbidities were compared across disease groups (HIV/HCV, HIV, $\mathrm{HCV}$ ). Survey logistic regressions were performed to determine factors associated with utilization of HIV therapy and utilization of HCV therapy. Coinfection status was entered into both models as an indicator variable, while adjusting for relevant demographic covariates. SAS procedures SURVEYFREQ, SURVEYMEANS, and SURVEYLOGISTIC were used where appropriate.

\section{Results}

Approximately, 11,352,000 clinic visits (3,021 unweighted observations) met study criteria for patients with HIV/ HCV coinfection (8\%), HIV monoinfection (70\%), or HCV monoinfection (22\%) between 2005 and 2010. A comparison of demographics, select comorbidities, and outpatient visit characteristics by infection group is presented in Table 1. In general, the HCV group was older in age and had the highest proportion of females and whites as compared to the HIV/HCV and HIV groups. Clinic visits predominantly occurred in the southern United States and the most common form of insurance coverage listed across all groups was Medicaid, followed by Medicare. The following comorbidities varied significantly across the three groups (HIV/HCV, HIV, HCV): current tobacco use (40\%, 27\%, $30 \%)$, depression $(32 \%, 23 \%, 24 \%)$, diabetes $(9 \%, 10 \%, 17 \%)$, and chronic renal failure $(<1 \%, 3 \%, 5 \%),(p<0.001$ for all variables). The majority of patients had previously established care at the clinic that they visited. Physicians often provided care at these visits (approximately 80\% for all three groups). By comparison, nurse practitioners and physician assistants provided care less often. In contrast, nurses provided care at approximately two-thirds of visits for the HIV/HCV and HIV groups, but only provided care at half of visits for the HCV group $(p<0.001)$. It was more common for those with $\mathrm{HIV} / \mathrm{HCV}$ to visit with their primary care provider/physician, as compared to those with either HIV monoinfection or HCV monoinfection.

For all study years, annual visit rates were highest in those with HIV, followed by HIV/HCV (Figure 1). Annual visit rates were consistently lower in those with $\mathrm{HCV}$. Documentation of HCV antiviral therapy utilization remained low for both $\mathrm{HIV} / \mathrm{HCV}$ and $\mathrm{HCV}$ groups for all years (Figure 2). Results from the logistic regression to identify predictors of $\mathrm{HCV}$ therapy are presented in Table 2. Presence of depression as a comorbidity was associated with decreased odds of HCV therapy (adjusted odds ratio [95\% CI]; 0.265 [0.131 - 0.536]). HIV/HCV coinfection (compared to HCV monoinfection) was not associated with HCV therapy. HIV antiretroviral therapy utilization increased for both HIV/HCV and HIV groups; the increase was more pronounced in the HIV/HCV group (Figure 3). Per regression analysis in Table 3, HIV/HCV coinfection (compared to having HIV alone) was associated with increased odds of HIV therapy ( $p<0.01$ in all years). Negative predictors of HIV therapy included African-American race/ethnicity $(p=0.045)$ and no charge for the clinic visit $(p=0.044)$.

\section{Discussion}

This is one of the first studies to compare outpatient utilization patterns for $\mathrm{HIV} / \mathrm{HCV}$ coinfection, HIV monoinfection and HCV monoinfection on a national perspective. One advantage to the observational nature of the study design is the generalizability of the findings. The study evaluated patterns of care in the outpatient setting and are therefore, more reflective of actual clinical practice as compared to results from studies that are conducted in a controlled setting. This study reveals that there are differences in utilization of outpatient services based on infection status (coinfection vs. monoinfection). Differences in demographic characteristics across the three groups noted in this study are consistent with prior studies. Patients with HIV tended to be younger in age [11], of male gender $[11,12]$, and of African-American race [11,12], as compared to patients with $\mathrm{HCV}$.

An unexpected finding was the variation of clinic visit rates by infection type; there were more visits for patients with HIV than for patients with $\mathrm{HCV}$, including those with coinfection. National surveillance data estimate that approximately 5.2 million persons in the United States 
Table 1 Comparison of demographics, select comorbidities, and outpatient visit characteristics in patients with HIV/ HCV, HIV, and HCV

\begin{tabular}{|c|c|c|c|c|}
\hline Characteristic & HIV/HCV coinfection & HIV monoinfection & HCV monoinfection & $P$-value \\
\hline No. of Unweighted Observations & 200 & 1992 & 829 & \\
\hline No. of Visits in 1000s ( $95 \% \mathrm{Cl}$ ) & $859(422-1296)$ & $7,926(4,772-11081)$ & 2,567 (1658-3476) & $<0.001$ \\
\hline Proportion of Study Visits & $8 \%$ & $70 \%$ & $22 \%$ & \\
\hline Patient demographics & - & - & - & \\
\hline Age (years), mean ( $95 \% \mathrm{Cl})$ & $46.4(43.1-49.7)$ & $42.9(41.6-44.2)$ & $50.4(49.0-51.9)$ & $<0.001$ \\
\hline Gender & - & - & - & $<0.001$ \\
\hline Male (\%) & 64 & 68 & 59 & - \\
\hline Female (\%) & 36 & 32 & 41 & - \\
\hline Race/ethnicity (\%) & - & - & - & $<0.001$ \\
\hline White & 31 & 25 & 56 & - \\
\hline African-American & 49 & 50 & 29 & - \\
\hline Hispanic & 18 & 23 & 11 & - \\
\hline Other & 1 & 2 & 4 & - \\
\hline Geographic region (\%) & - & - & - & $<0.001$ \\
\hline Northeast & 30 & 26 & 28 & - \\
\hline Midwest & 11 & 18 & 9 & - \\
\hline West & 7 & 12 & 10 & - \\
\hline South & 52 & 43 & 53 & - \\
\hline Insurance status (\%) & - & - & - & 0.051 \\
\hline Private & 4 & 16 & 23 & - \\
\hline Medicare & 20 & 16 & 14 & - \\
\hline Medicaid & 45 & 43 & 31 & - \\
\hline Other/unknown & 11 & 11 & 10 & - \\
\hline Self-pay & 3 & 4 & 8 & - \\
\hline No Charge & 17 & 9 & 14 & - \\
\hline Comorbidities & - & - & - & - \\
\hline Chronic Renal Failure (\%) & $<1$ & 3 & 5 & $<0.001$ \\
\hline Depression (\%) & 32 & 23 & 24 & $<0.001$ \\
\hline Diabetes (\%) & 9 & 10 & 17 & $<0.001$ \\
\hline Current Tobacco Use (\%) & - & - & - & $<0.001$ \\
\hline Yes & 40 & 27 & 30 & - \\
\hline No & 28 & 28 & 38 & - \\
\hline Unknown & 32 & 45 & 32 & - \\
\hline Visit characteristics & - & - & - & - \\
\hline Established Patient (\%) & 94 & 93 & 83 & $<0.001$ \\
\hline Patient's Primary Care Physician/Provider (\%) & - & - & - & $<0.001$ \\
\hline Yes & 48 & 36 & 35 & - \\
\hline No & 49 & 58 & 60 & - \\
\hline Unknown & 3 & 6 & 5 & - \\
\hline Providers Seen (\%) & - & - & - & - \\
\hline Physician & 81 & 79 & 80 & 0.5 \\
\hline RN/LPN & 63 & 64 & 54 & $<0.001$ \\
\hline
\end{tabular}


Table 1 Comparison of demographics, select comorbidities, and outpatient visit characteristics in patients with HIV/ HCV, HIV, and HCV (Continued)

\begin{tabular}{|c|c|c|c|c|}
\hline Nurse practitioner/midwife & 14 & 13 & 14 & 0.2 \\
\hline Physician assistant & 4 & 4 & 4 & 0.6 \\
\hline Other & 23 & 25 & 20 & $<0.001$ \\
\hline
\end{tabular}

are chronically infected with $\mathrm{HCV}$, whereas approximately 1.1 million persons in the United States are infected with HIV [13,14]. The epidemiologic burden of HCV is greater than that of HIV, but utilization of outpatient care was relatively low for this patient population. In addition, it is estimated that one quarter of individuals living with HIV are coinfected with HCV [15]. Given that HIV requires lifelong management, and therefore necessitates routine outpatient care, one would expect that patients with HIV/ $\mathrm{HCV}$ visit the clinic at least to the same extent as patients with only HIV. From a public health standpoint, this implies that coinfected individuals are not entering into care at the same rate as HIV monoinfected individuals. Low utilization of outpatient services precludes coinfected patients from receiving timely antiviral or antiretroviral therapies, leading to increased utilization of acute care services such as emergency department visits and hospital admissions [16]. These findings highlight the need to reduce entry to care barriers for this patient population.

Outpatient prescriptions for antiviral therapy was quite low across both groups with HCV. However, utilization was slightly lower for those with coinfection compared to those with monoinfection ( $7 \%$ vs. $10 \%$, respectively). Uptake of HCV therapy has historically been low. Two separate studies by Cheung et al. [17] and Tsui et al. [18] sought to evaluate antiviral treatment rates for outpatient visits in patients with $\mathrm{HCV}$, using national survey data. Both investigators reported that fewer than $10 \%$ of all HCV-related patient visits documented antiviral therapy. Data from these two studies were only through 2006, whereas data from the present investigation are through 2010. Nevertheless, the findings still persist; antiviral treatment rates in the United States have remained unchanged over the past several years. More efforts are needed to improve $\mathrm{HCV}$ treatment utilization rates.

The studies by Cheung et al. and Tsui et al. did not make a distinction for patients with monoinfection vs. patients with coinfection. Patients that are dually infected tend to experience accelerated progression of end-stage liver disease leading to increased risk of morbidity and mortality [5,6,19-21]. This distinction is important given their unique, clinical needs. Butt et al. conducted an investigation to compare treatment rates in patients with monoinfection vs. patients with coinfection [12]. Eligible patients were recruited and referred for $\mathrm{HCV}$ care to infectious diseases/HIV and hepatology clinics. Given that these patients were prospectively referred for $\mathrm{HCV}$ care to specialty clinics, it is not surprising that the overall treatment rate was relatively high at $50 \%$. Nevertheless, the investigators determined that $\mathrm{HCV}$ treatment rates were lower in patients with coinfection compared to patients with monoinfection $(32 \%$ vs. $62 \% ; p<0.001)$. Coinfection status was also independently associated with a decreased likelihood of $\mathrm{HCV}$ treatment, despite controlling for factors in

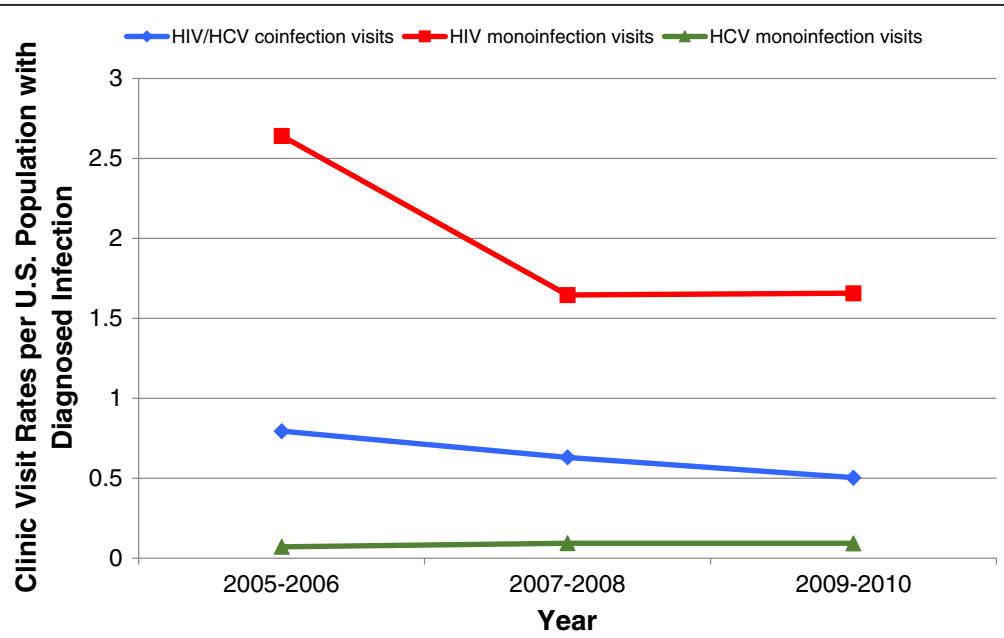

Figure 1 Trends in annual outpatient clinic visit rates for patients with HIV/HCV, HIV, or HCV infection. 


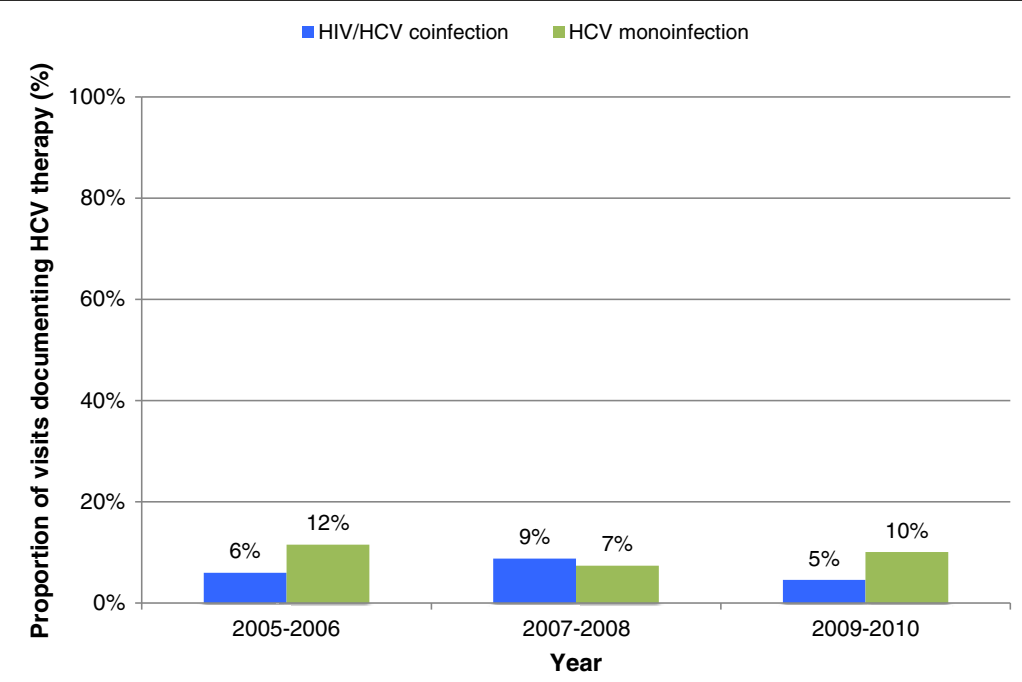

Figure 2 Clinic visits that documented HCV antiviral therapy prescription (HIV/HCV vs. HCV).

Table 2 Multivariate regression analysis of factors associated with HCV antiviral therapy

Age
Gender
Female
Male
Race
White, non Hispanic
African-American, non Hispanic
Hispanic
Other
Region
Northeast
Midwest
West
South

Insurance

Private Insurance

Medicare

Medicaid

Other/unknown

Self-pay

No Charge

Depression

HIV/HCV Coinfection vs. HCV Monoinfection

2005-2006 (year of visit)

2007-2008 (year of visit)

$0.5145(0.148,1.789)$ multivariate analysis (adjusted OR 0.33, 95\% CI 0.21-0.53). Lower treatment rates for patients with $\mathrm{HIV} / \mathrm{HCV}$ receiving care in specialized settings have been reported elsewhere. Scott et al. conducted a retrospective evaluation of HCV therapy in a cohort of HIV patients receiving primary care at a HIV specialty clinic [22]. Only 16\% of clinic patients ever received antiviral therapy. Similar proportions were noted in longitudinal data from the HIV Outpatient Study (HOPS); only 20\% of 507 patients with confirmed coinfection initiated $\mathrm{HCV}$ treatment during the period of observation [6]. While an increasing proportion of HOPS participants were treated over the 3-year baseline periods in 1999-2001 (19\%), 2002-2004 (21\%) and $2005-2007(28 \%)$, this overall rise was not statistically significant $(p=0.3)$. However, time for treatment initiation following confirmed $\mathrm{HCV}$ diagnosis decreased significantly $(p<0.001)$. Collectively, these findings underscore the ongoing issue of low HCV treatment uptake, particularly in patients with coinfection.

According to guideline recommendations, the primary goal of HCV therapy is to achieve a sustained virologic response (SVR) six months post treatment $[23,24]$. Such a response is effectively consistent with $\mathrm{HCV}$ cure for patients and greatly reduces progression to end-stage liver disease, hepatocellular carcinoma (HCC), and death [25-27]. To achieve this goal, therapy should be considered for all patients with chronic HCV. Pre-treatment assessments should be performed as certain conditions may preclude patients from receiving therapy. For instance, treatment is not recommended for patients with decompensated liver disease, severe uncontrolled psychiatric illness, and current alcohol and/or substance abuse [23]. Historically, antiviral treatment rates have been low due to concerns of side effects and/or adverse events associated with $\mathrm{HCV}$ standard of care with pegylated interferon 


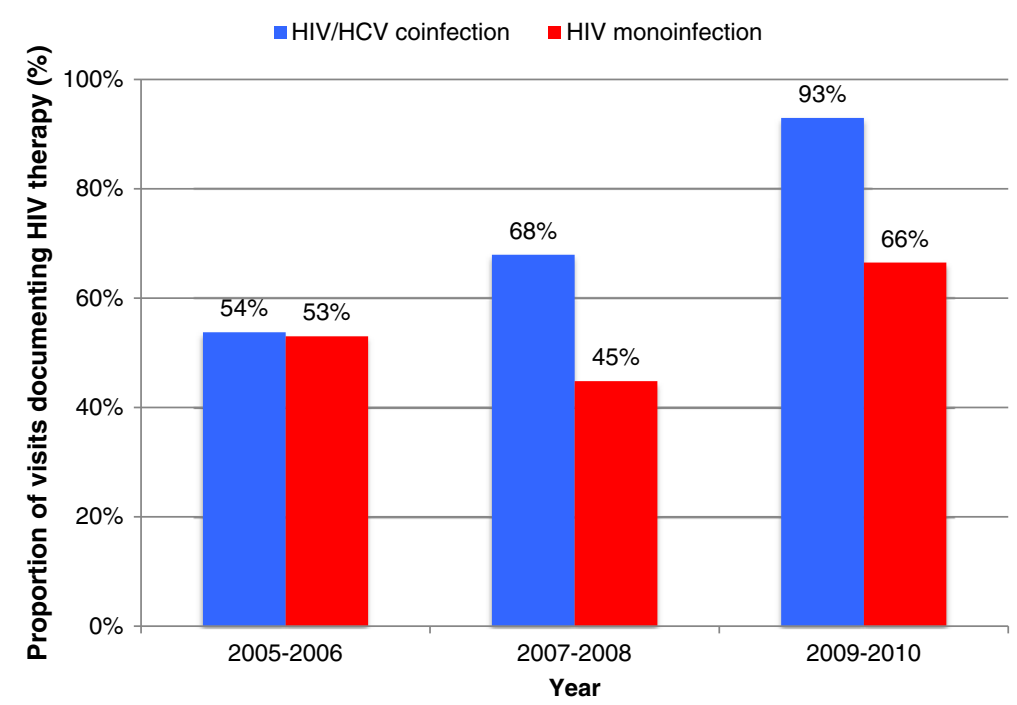

Figure 3 Clinic visits that documented HIV antiretroviral therapy prescription (HIV/HCV vs. HIV).

Table 3 Multivariate regression analysis of factors associated with HIV antiretroviral therapy

\begin{tabular}{|c|c|c|}
\hline & Adjusted OR $(95 \% \mathrm{Cl})$ & $P$-value \\
\hline Age & $1.012(0.998,1.025)$ & 0.1024 \\
\hline \multicolumn{3}{|l|}{ Gender } \\
\hline Female & 1 & - \\
\hline Male & $1.306(0.823,2.073)$ & 0.2571 \\
\hline \multicolumn{3}{|l|}{ Race } \\
\hline White, non Hispanic & 1 & - \\
\hline African-American, non Hispanic & $0.682(0.500,0.932)$ & 0.4559 \\
\hline Hispanic & $0.795(0.486,1.301)$ & 0.9695 \\
\hline Other & $0.759(0.211,2.725)$ & 0.9097 \\
\hline \multicolumn{3}{|l|}{ Region } \\
\hline Northeast & 1 & - \\
\hline Midwest & $1.271(0.545,2.966)$ & 0.211 \\
\hline West & $0.442(0.137,1.421)$ & 0.098 \\
\hline South & $1.148(0.589,2.238)$ & 0.2706 \\
\hline \multicolumn{3}{|l|}{ Insurance } \\
\hline Private Insurance & 1 & - \\
\hline Medicare & $0.87(0.588,1.286)$ & 0.1827 \\
\hline Medicaid & $0.547(0.298,1.005)$ & 0.0526 \\
\hline Unknown/other & $0.602(0.324,1.119)$ & 0.0531 \\
\hline Self-pay & $0.521(0.216,1.258)$ & 0.1352 \\
\hline No Charge & $0.629(0.398,0.996)$ & 0.0437 \\
\hline \multicolumn{3}{|l|}{$\begin{array}{l}\text { HIV/HCV Coinfection vs. HIV } \\
\text { Monoinfection }\end{array}$} \\
\hline 2005-2006 (year of visit) & $2.533(1.618,3.965)$ & $<.0001$ \\
\hline 2007-2008 (year of visit) & $7.464(1.9,29.317)$ & 0.004 \\
\hline 2009-2010 (year of visit) & $2.888(1.364,6.117)$ & 0.0056 \\
\hline
\end{tabular}

and ribavirin (pegIFN + RBV). Reported adverse events often include hemolytic anemia associated with ribavirin use and influenza-like symptoms and neuropsychiatric effects associated with interferon use [23]. Fortunately, improved direct-acting antiviral (DAA) agents are associated with improved SVR rates and are now guideline-endorsed for use in combination with pegIFN + RBV [24]. The possibility of IFN-free regimens is also on the horizon [28]. For current clinical practice, particularly for those with coinfection, pegIFN + RBV are still a key component of the regimen. It has been projected that the addition of DAA agents to pegIFN + RBV will actually increase regimen complexity over the next few years as data emerge from clinical trials [20,29]. Other treatment considerations still include the concern for increased pill burden and the potential for drug-drug interactions with HCV medications and concomitant administration of antiretroviral therapy. Efforts are needed to improve HCV treatment utilization rates, particular in patients with coinfection.

Outpatient antiretroviral therapy increased in both groups with HIV. The goals of antiretroviral therapy include viral suppression, transmission prevention, and the restoration and preservation of immune function [30]. Since the eradication of the virus is not achieved by available antiretroviral medications, duration of HIV therapy is considered to be a lifelong commitment. It is expected that HIV therapy utilization was greater than HCV therapy utilization at the time of clinic visit. Other studies have reported high and/or rising use of HIV therapy, in both coinfection and monoinfection [6,11,31]. With regards to those with $\mathrm{HIV} / \mathrm{HCV}$, the majority (87\%) of patients in the aforementioned HOPS study had some form of prior exposure to antiretroviral therapy [6]. High use is consistent with national treatment guidelines which now 
recommend antiretroviral therapy for all HIV-infected individuals, regardless of CD4 cell count, to reduce the risk of disease progression and for the prevention of the HIV transmission [30]. Fortunately, the advent of newer antiretroviral medications has lessened the concern for regimen complexity, drug-drug interactions, and pill burden. In the present study, the rise in antiretroviral coverage was more pronounced for those with coinfection, with the proportion rising from $54 \%$ in $2005-2006$ to $93 \%$ in 2009-2010. This finding implies that HIV treatment is improving for this patient population. However, this only applies to patients that are in care. As described earlier, it was expected that the coinfection clinic visit rate would mirror that of the HIV monoinfection rate, but in fact, the rate was lower. Continued efforts are needed to engage patients diagnosed with $\mathrm{HIV} / \mathrm{HCV}$ coinfection into outpatient care.

One of our findings was that African-American race/ ethnicity was associated with lower odds of HIV antiretroviral therapy. Racial disparities in access to regular HIV care still persist; African-Americans have been shown to have sub-optimal engagement in the HIV continuum of care, particularly African-American males and African-American youth [32]. Gaston et al. recently conducted a systematic review to understand factors that influence engagement and adherence to HIV medical care among African-Americans [33]. A review of the 16 studies revealed that lack of social support, perceived discrimination and racism, and conspiracy beliefs about HIV and related treatments were barriers to HIV care, whereas, good quality relationships with health care providers facilitated adherence to HIV-related care [33].

Engagement in outpatient care is key for the management of both HIV and HCV. Despite recent and emerging advances in treatment, barriers to care persist, particularly for $\mathrm{HCV}$ care. The most common barriers are at the systems level (e.g., limited infrastructure for assessment and treatment, accessing care, high treatment costs), provider level (e.g., perceptions of poor patient adherence, concerns for active drug abusers, lack of experience treating patients), and at the patient level (e.g., lack of knowledge, misconceptions, level of motivation) $[20,34]$. Potential strategies to improve engagement in care include routine $\mathrm{HCV}$ testing and linking patients to care immediately following diagnosis. Furthermore, HCV care services can be expanded to other primary care services, which can be accomplished through cross-specialty provider education and training and patient pretreatment education [35]. Future research should delve further into outpatient utilization patterns to evaluate differences in contextual factors, adherence to prescribed medications, and patient-perceived barriers to care. A comprehensive approach that addresses these barriers can help to improve entry to outpatient care.
This study is subject to some limitations. The multivariate analysis conducted within this study should be interrupted carefully. The NHAMCS are designed to provide population-level estimates. Certain patient-levels factors that can be helpful in determining treatment initiation were unavailable. As such, multivariate analyses in this study did not adjust for HCV genotype, viral load, CD4 cell count, and patients' medical history. Additionally, despite spanning 13 years, the study was not longitudinal and could not assess which patients were continuing with care over time. Findings represent only a snapshot in time and it is difficult to infer future trends. The NHAMCS data are presented as visit-level data rather than patient-level data; it is possible that the analysis captures patients that are sampled multiple times. However, only a patient returning to the clinic within the four-week reporting interval would potentially be sampled more than once. The NHAMCS survey instrument has a restriction on the maximum number of medications; no more than eight medications can be documented at time of visit. It is not uncommon for patients with HIV or HCV to use multiple medications. Therefore, we did not assess regimen appropriateness; rather, we evaluated documentation of any antiviral or antiretroviral medication. Up until 2005, medications were coded based on a 5-digit drug code. Starting in 2006, medications were coded based on a 6-digit code (in addition to the 5 digit code). We cross-referenced all codes to ensure accuracy in identifying medications.

Data regarding physician specialty (e.g., hepatologist, infectious diseases specialist) and detailed patient histories (e.g., past medication histories, prior treatment response, objective laboratory data) were not available in these surveys. Rather, we were able to assess patients that were visiting their primary care physician/provider as well as other types of health care professionals that provided care during the visit. Other providers in the U.S., such as nurse practitioners and physician assistants, have prescriptive authority when practicing under the direction of a supervising physician. Including the various types of providers seen is an indicator for a multidisciplinary approach to care for these patients. Moreover, we found that the majority of all patients had previously established care at the clinics that they visited, which is indicative of continued engagement in care at that facility.

\section{Conclusions}

These data provide national, population-level estimates for health care utilization trends in patients with HIV/ $\mathrm{HCV}, \mathrm{HIV}$, or HCV. Patients with coinfection have different medical needs compared to those with HIV or $\mathrm{HCV}$ alone. Nevertheless, prescription of HCV therapy remains low in the outpatient setting. While HIV therapy utilization was greater in patients with $\mathrm{HIV} / \mathrm{HCV}$ 
than those with HIV, consistently lower clinic visit rates for the latter group reveal a disparity in the use of outpatient services. There is a critical need for system-level interventions that reduce barriers to care. Such efforts can improve treatment-related outcomes for this patient population. Future studies should investigate how health care utilization and $\mathrm{HCV}$-related outcomes differ for patients with $\mathrm{HIV} / \mathrm{HCV}$ compared to patients with $\mathrm{HCV}$ monoinfection, specifically in the context of DAA-based antiviral therapy.

\section{Competing interests}

The authors declare that they have no competing interests.

\section{Authors' contributions}

CO was the senior investigator on the manuscript; she contributed substantially to the design of the research study, data acquisition, interpretation of data analysis, and drafting the manuscript. TJ contributed significantly to the study design, data analysis, data interpretation, organizing and drafting the manuscript. LM conducted the data analysis, assisted in interpretation of the analysis, and drafting the manuscript. JT participated in the study design, data acquisition, data analysis, and drafting the manuscript. All authors have reviewed and approved the final manuscript.

\section{Acknowledgements}

This work was presented in part at the International Society for Pharmacoeconomics and Outcomes Research annual meeting, New Orleans, LA. This study was funded in full by The University of North Carolina Junior Faculty Development Award received by Christine U. Oramasionwu.

\section{Author details}

'University of North Carolina, UNC Eshelman School of Pharmacy, Division of Pharmaceutical Outcomes and Policy, Chapel Hill, NC 27599-7355, 2215 Kerr Hall, USA. ${ }^{2}$ University of North Carolina, UNC Gillings School of Global Public Health and the UNC Center for AIDS Research (CFAR) Biostatistics Core, Chapel Hill, NC, USA.

Received: 19 March 2014 Accepted: 9 April 2014

Published: 23 April 2014

\section{References}

1. Linas BP, Wang B, Smurzynski M, Losina E, Bosch RJ, Schackman BR, Rong J, Sax PE, Walensky RP, Schouten J, Freedberg KA: The impact of HIV/HCV co-infection on health care utilization and disability: results of the ACTG Longitudinal Linked Randomized Trials (ALLRT) Cohort. J Viral Hepat 2011, 18(7):506-512

2. Katzenstein DA, Hammer SM, Hughes MD, Gundacker H, Jackson JB, Fiscus $S$, Rasheed S, Elbeik T, Reichman R, Japour A, Merigan TC, Hirsch MS: The relation of virologic and immunologic markers to clinical outcomes after nucleoside therapy in HIV-infected adults with 200 to 500 CD4 cells per cubic millimeter. AIDS Clinical Trials Group Study 175 Virology Study Team. N Engl J Med 1996, 335(15):1091-1098.

3. McHutchison JG, Gordon SC, Schiff ER, Shiffman ML, Lee WM, Rustgi VK Goodman ZD, Ling MH, Cort S, Albrecht JK: Interferon alfa-2b alone or in combination with ribavirin as initial treatment for chronic hepatitis $\mathrm{C}$. Hepatitis Interventional Therapy Group. N Engl J Med 1998, 339(21):1485-1492.

4. Torriani FJ, Rodriguez-Torres M, Rockstroh JK, Lissen E, Gonzalez-Garcia J, Lazzarin A, Carosi G, Sasadeusz J, Katlama C, Montaner J, Sette H Jr, Passe S, De Pamphilis J, Duff F, Schrenk UM, Dieterich DT, APRICOT Study Group: Peginterferon Alfa-2a plus ribavirin for chronic hepatitis C virus infection in HIV-infected patients. N Engl J Med 2004, 351(5):438-450.

5. Ananthakrishnan AN, McGinley EL, Fangman J, Saeian K: Hepatitis C/HIV co-infection is associated with higher mortality in hospitalized patients with hepatitis C or HIV. J Viral Hepat 2010, 17(10):720-729.

6. Vellozzi C, Buchacz K, Baker R, Spradling PR, Richardson J, Moorman A, Tedaldi E, Durham M, Ward J, Brooks JT: Treatment of hepatitis $C$ virus
(HCV) infection in patients coinfected with HIV in the HIV Outpatient Study (HOPS), 1999-2007. J Viral Hepat 2011, 18(5):316-324.

7. Agency for Healthcare Research and Quality: 2012 National Healthcare Disparities Report. June 2013. Available at http://www.ahrq.gov/research/ findings/nhqrdr/nhdr12/index.html. Accessed March 17, 2014

8. McCaig LF, Burt CW: Understanding and interpreting the National Hospital Ambulatory Medical Care Survey: key questions and answers. Ann Emerg Med 2012, 60(6):716-721. e711.

9. Centers for Medicare \& Medicaid Services: Medicaid Eligibility. Available at http://www.medicaid.gov/Medicaid-CHIP-Program-Information/By-Topics/ Eligibility/Eligibility.html. Accessed March 5, 2014.

10. Centers for Medicare \& Medicaid Services: Medicare Program: General Information. Available at http://www.cms.gov/Medicare/Medicare-GeneralInformation/MedicareGenInfo/index.html. Accessed March 5, 2014

11. Kakinami L, Block RC, Adams MJ, Cohn SE, Maliakkal B, Fisher SG: Risk of cardiovascular disease in HIV, hepatitis $\mathrm{C}$, or HIV/hepatitis C patients compared to the general population. Int I Clin Pract 2013, 67(1):6-13.

12. Butt AA, Tsevat J, Leonard AC, Shaikh OS, McMahon D, Khan UA, DoreyStein Z, Lo Re V III: Effect of race and HIV co-infection upon treatment prescription for hepatitis C virus. Int J Infect Dis 2009, 13(4):449-455.

13. Chak E, Talal AH, Sherman KE, Schiff ER, Saab S: Hepatitis C virus infection in USA: an estimate of true prevalence. Liver Int 2011, 31(8):1090-1101.

14. Centers for Disease Control and Prevention: HIV Surveillance Report, 2011; vol. 23. Available at: http://www.cdc.gov/hiv/topics/surveillance/resources/ reports/ Published February 2013. Accessed January 22, 2014.

15. Centers for Disease Control and Prevention: HIV/AIDS and Viral Hepatitis. http://www.cdc.gov/hepatitis/Populations/hiv.htm. Accessed March 17, 2014

16. Norton BL, Park L, McGrath LJ, Proeschold Bell RJ, Muir AJ, Naggie S: Health care utilization in HIV-infected patients: assessing the burden of hepatitis C virus coinfection. AIDS Patient Care STDS 2012, 26(9):541-545.

17. Cheung R, Mannalithara A, Singh G: Utilization and antiviral therapy in patients with chronic hepatitis C: analysis of ambulatory care visits in the US. Dig Dis Sci 2010, 55(6):1744-1751.

18. Tsui Jl, Maselli J, Gonzales R: Sociodemographic trends in national ambulatory care visits for hepatitis C virus infection. Dig Dis Sci 2009, 54(12):2694-2698.

19. Chen TY, Ding EL, Seage lii GR, Kim AY: Meta-analysis: increased mortality associated with hepatitis C in HIV-infected persons is unrelated to HIV disease progression. Clin Infect Dis 2009, 49(10):1605-1615.

20. Grebely J, Oser M, Taylor LE, Dore GJ: Breaking down the barriers to hepatitis $\mathrm{C}$ virus (HCV) treatment among individuals with HCV/HIV coinfection: action required at the system, provider, and patient levels. $J$ Infect Dis 2013, 207(Suppl 1):S19-S25.

21. Limketkai BN, Mehta SH, Sutcliffe CG, Higgins YM, Torbenson MS, Brinkley SC, Moore RD, Thomas DL, Sulkowski MS: Relationship of liver disease stage and antiviral therapy with liver-related events and death in adults coinfected with HIV/HCV. JAMA 2012, 308(4):370-378

22. Scott JD, Wald A, Kitahata M, Krantz E, Drolette L, Corey L, Wang CC Hepatitis $\mathrm{c}$ virus is infrequently evaluated and treated in an urban HIV clinic population. AIDS Patient Care STDS 2009, 23(11):925-929.

23. Panel on Opportunistic Infections in HIV-Infected Adults and Adolescents: Guidelines for the prevention and treatment of opportunistic infections in HIV-infected adults and adolescents: recommendations from the Centers for Disease Control and Prevention, the National Institutes of Health, and the HIV Medical Association of the Infectious Diseases Society of America. http://aidsinfo.nih.gov/contentfiles/lvguidelines/adult_oi.pdf. Accessed March 12, 2014

24. American Association for the Study of Liver Diseases and the Infectious Diseases Society of America: Recommendations for testing, managing, and treating hepatitis C. Available at http://www.hcvguidelines.org/fullreport-view. Accessed March 17, 2014

25. Swain MG, Lai MY, Shiffman ML, Cooksley WG, Zeuzem S, Dieterich DT, Abergel A, Pessoa MG, Lin A, Tietz A, Connell EV, Diago M: A sustained virologic response is durable in patients with chronic hepatitis $C$ treated with peginterferon alfa-2a and ribavirin. Gastroenterology 2010, 139(5):1593-1601.

26. Berenguer J, Alvarez-Pellicer J, Martin PM, Lopez-Aldeguer J, Von-Wichmann MA, Quereda C, Mallolas J, Sanz J, Tural C, Bellon JM, González-García J: Sustained virological response to interferon plus ribavirin reduces liver-related complications and mortality in patients coinfected with human immunodeficiency virus and hepatitis C virus. Hepatology 2009, 50(2):407-413. 
27. Morgan TR, Ghany MG, Kim HY, Snow KK, Shiffman ML, De Santo JL, Lee WM, Di Bisceglie AM, Bonkovsky HL, Dienstag JL, Morishima C, Lindsay KL, Lok AS, HALT-C Trial Group: Outcome of sustained virological responders with histologically advanced chronic hepatitis C. Hepatology 2010, 52(3):833-844.

28. Dore GJ: The changing therapeutic landscape for hepatitis C. Med J Aust 2012, 196(10):629-632.

29. Taylor LE, Swan T, Mayer KH: HIV coinfection with hepatitis C virus: evolving epidemiology and treatment paradigms. Clin Infect Dis 2012, 55(Suppl 1):S33-S42.

30. Panel on Antiretroviral Guidelines for Adults and Adolescents: Guidelines for the use of antiretroviral agents in HIV-1-infected adults and adolescents. Department of Health and Human Services. http://aidsinfo.nih.gov/ ContentFiles/AdultandAdolescentGL.pdf. Accessed March 12, 2014.

31. Oramasionwu CU, Brown CM, Lawson KA, Ryan L, Skinner J, Frei CR Differences in national antiretroviral prescribing patterns between black and white patients with HIV/AIDS, 1996-2006. South Med J 2011, 104(12):794-800

32. Whiteside YO, Cohen SM, Bradley H, Skarbinski J, Hall HI, Lansky A: Progress along the continuum of HIV care among blacks with diagnosed HIVUnited States, 2010. MMWR Morb Mortal Wkly Rep 2014, 63(5):85-89.

33. Gaston GB, Alleyne-Green B: The impact of African Americans' beliefs about HIV medical care on treatment adherence: a systematic review and recommendations for interventions. AIDS Behav 2013, 17(1):31-40.

34. Wagner G, Ryan G, Osilla KC, Bhatti L, Goetz M, Witt M: Treat early or wait and monitor? A qualitative analysis of provider hepatitis $C$ virus treatment decision-making in the context of HIV coinfection. AIDS Patient Care STDS 2009, 23(9): :715-725.

35. U.S. Department of Health and Human Services: Combating the silent epidemic of viral hepatitis: action plan for the prevention, care, and treatment of viral hepatitis. Washington, DC: U.S: Department of Health and Human Services; 2011:1-76.

doi:10.1186/1471-2334-14-217

Cite this article as: Johnson et al:: Differences in outpatient care and treatment utilization for patients with HIV/HCV coinfection, HIV, and HCV monoinfection, a cross-sectional study. BMC Infectious Diseases 2014 14:217.

\section{Submit your next manuscript to BioMed Central and take full advantage of:}

- Convenient online submission

- Thorough peer review

- No space constraints or color figure charges

- Immediate publication on acceptance

- Inclusion in PubMed, CAS, Scopus and Google Scholar

- Research which is freely available for redistribution 